\title{
Críticas al arbitraje de inversiones y las soluciones a plantearse
}

\author{
Blanca Gómez de la Torre* \\ Recibido/Received: 29/01/2016 \\ Aceptado/Accepted: 19/08/2016
}

SUMARIO: 1. Introducción. 2. Las críticas al arbitraje de inversiones. 2.1 Consistencia. 2.2 Legitimidad. 3. Reformas al arbitraje de inversiones. 3.1 La reforma a los tratados. 3.2 La inclusión de una fase de apelación dentro del Tratado Transatlántico de Comercio e Inversiones entre la Unión Europea y Estados Unidos. 4. Conclusiones.

PALABRAS CLAVE: Arbitraje de inversiones, reformas, inconsistencia, legitimidad, jurisprudencia.

KEYWORDS: Investment arbitration, amendments, inconsistency, legitimacy, case-law.

RESUMEN: El arbitraje de inversiones fue creado como un mecanismo para salvaguardar la confianza de los inversionistas en caso de existir conflictos respecto a sus inversiones. Sin embargo, este mecanismo ha presentado varias falencias por diversos motivos, tales como la falta de consistencia de las decisiones tomadas, el lenguaje amplio de los tratados de protección de inversiones, la imparcialidad de los árbitros, los costos que representa un proceso como este, y la legitimi-

* Abogada y Doctora por la Pontifica Universidad Católica del Ecuador. Directora Nacional de Asuntos Internacionales y Arbitraje, Procuraduría General del Estado.

B. Gómez DE LA TORRE, "Críticas al arbitraje de inversiones y las soluciones a plantearse", Revista Ecuatoriana de Arbitraje, No. 7, 2015. 
dad del sistema. Existen varias propuestas para dar solución a estos conflictos, no obstante, estas posibles soluciones reciben críticas y cuestionamientos de varios sectores. De esta manera, se analizarán los puntos expuestos con la finalidad de determinar si una reforma, realmente generaría un cambio.

ABSTRACT: The investment arbitration mechanism was created in order to protect the investor confidence in case of a dispute respect their inversion. Furthermore, this system has several miscalculations, such as the inconsistency regarding the decisions taken by different tribunals, arbitrators impartiality, the high costs this procedure takes, and its legitimacy. As a response, possible amendments were suggested; nonetheless, they are criticized as well. In order to determine if investment arbitration system can apply them or not, miscalculations previously mentioned will be analyzed, including the possible solutions.

\section{INTRODUCCIÓN}

El arbitraje de inversiones nace como una alternativa a la desconfianza generada para los inversionistas de que los conflictos que se generen por su inversión sean manejados por los órganos jurisdiccionales del país receptor de la inversión, transformándose este Estado en juez y parte del conflicto posiblemente originado por el mismo. A eso se añade, la desconfianza del país receptor de la misma a que este conflicto sea juzgado por leyes extrañas en jurisdicción del país emisor de la inversión. Se trata entonces de adaptar al tratamiento de las inversiones un sistema de resolución de conflictos que había funcionado bien para los comerciantes, el arbitraje comercial confidencial ad hoc, el que para cuestiones de fondo y por la propia dinámica de la actividad comercial no contempla la posibilidad de que los Estados ejerzan control jurisdiccional a través de mecanismos como la apelación. Asimismo, este nuevo mecanismo tiene la posibilidad de tener sus propias reglas originadas en los tratados que para el efecto 
celebrarían los Estados interesados en ofrecer esta alternativa a los inversionistas.

Esta propuesta que sonaba razonable en los años cincuenta, en su implementación y resultados ha generado una serie de críticas en vista de que aquellos tratados que supuestamente, constituyen su columna vertebral fueron redactados en sus inicios con proposiciones vagas y términos amplios que han sido interpretados muchas veces más allá de la voluntad del Estado involucrado en la disputa de inversiones. Asimismo, los tribunales arbitrales al constituirse en órganos aislados cuyas decisiones son finales y no pueden ser objeto de revisión posterior han gozado de una discrecionalidad que les ha permitido inconsistencias en sus decisiones e interpretaciones que van más allá de sus potestades invadiendo campos reservados para las políticas públicas de los Estados.

Todo ello, ha generado una creciente crítica a la legitimidad y conveniencia de esta herramienta de resolución de conflictos, y ante ello se plantean alternativas como su abandono definitivo o una indispensable reforma. Sin embargo, esta reforma no es fácil pues al ser un mecanismo atomizado originado en más de $3271^{1}$ tratados de protección de inversiones suscritos en más de cincuenta años de desarrollo de la herramienta, su cambio involucra la enmienda del mismo número de tratados y nuevamente, la prueba y error de esta nueva normativa.

Un número creciente de países proponen la implementación de un sistema de apelación que permita que la inconsistencia que se constituye en el mayor pecado de este mecanismo se supere gracias al control y supervisión de un segundo juzgador, pero esto también conlleva sus riesgos y detractores. Así se proponen alternativas como Tribunales permanentes o Tribunales constituidos específicamente para el efecto. Esta posibilidad, conlleva nuevos gastos, nueva institucionalidad y mayor tiempo para la resolución definitiva del conflicto.

1. United Nations Conference on Trade and Development (UNCTAD), "Reforming International Investment Governance" World Investment Report, 2015, p. 121. 
En el año 2015 se genera por parte de la Comisión de Comercio de la Unión Europea una propuesta de texto a ser incorporado al Tratado Transatlántico de Comercio e Inversiones entre la Unión Europea y Estados Unidos (TTIP) que ha generado una serie de opiniones y críticas sobre la forma en que se plantea el mecanismo de solución de controversias entre inversores y Estados, denominado Investment Court System (ICS) tal mecanismo que contempla entre otras innovaciones una posibilidad de apelación ante una Corte de Jueces creada por este mismo tratado será analizado en el desarrollo del presente trabajo.

\section{LAS CRÍticAS AL ARBITRAJE DE INVERSIONES}

Si nos atenemos a los números, de acuerdo a las estadísticas de la Conferencia de las Naciones Unidas sobre el Comercio y el Desarrollo de $2015^{2}$, hasta finales del 2014, los inversionistas han iniciado 608 casos de arbitraje inversionistas-Estado basados en los Tratados de Protección de Inversiones, se ha demandado a 99 países, 70\% de estos casos se han iniciado contra países en desarrollo y el $80 \%$ de ellos se refieren a reclamos de inversionistas de países desarrollados. Adicionalmente, en estos últimos años se han incrementado los casos contra Estados desarrollados. Los montos reclamados por caso alcanza en promedio los mil millones de dólares de los Estados Unidos de América. Con esto en mente, el discurso público acerca de la utilidad y legitimidad del arbitraje de inversiones llega a uno de sus puntos más altos, especialmente en el contexto de importantes negociaciones de acuerdos que se encuentran en discusión como es el caso del ya referido TTIP.

En este contexto, pasaremos a examinar dos puntos principales: 1) Consistencia en las decisiones y 2) legitimidad. 


\subsection{Consistencia ${ }^{3}$}

La inconsistencia en las decisiones es un problema cada vez más creciente en el arbitraje de inversiones. El hecho de que existan procedimientos paralelos y que las excepciones de litis pendencia y cosa juzgada tengan una aplicación limitada son factores que permiten este fenómeno.

Entendemos por inconsistencia la situación en que diferentes tribunales llegan a diferentes conclusiones a pesar de existir similitudes en los hechos y el derecho aplicable a los casos ${ }^{4}$. Existen situaciones tales como CMS c. Argentina y LG\&E c. Argentina relacionados al estado de necesidad ${ }^{5}$, o el paradigmático CME c. República Checa y Lauder c. República Checa denominados por el Profesor August ReINISCH como "el último fiasco del arbitraje de inversiones" ${ }^{\prime \prime}$.

Existe una serie de escenarios en donde pueden darse decisiones inconsistentes. El primero de ellos puede darse por la similitud de hechos, la misma ley aplicable y conclusiones legales diferentes en alguno de los puntos resueltos. Un segundo escenario puede darse frente a hechos similares, similar ley aplicable y una decisión conflictiva relacionada a uno de los elementos decididos en el arbitraje. Inclusive la inconsistencia puede darse en

3. B. Gómez de la Torre, The Practice of International Arbitration: Ecuador's Perspective, UCL, 11 de noviembre de 2014.

4. J. Vinaules and F. SPOOREnBerg, "Conflicting decisions in international arbitration", in The law and practice of international courts and tribunals, 2009, p. 92.

5. Las diferentes conclusiones encontradas en el asunto de estado de necesidad en los laudos de CMS y LG\&E proveen una clara ilustración del efecto destructor de tal contradicción. Como una reacción a la crisis económica argentina que transcurrió desde el año 1999, el gobierno decidió suspender el ajuste tarifario semestral por IPP y congelar las tarifas de distribución de gas. Estas medidas llevaron a un número de inversionistas norteamericanos en el sector del gas, entre los que estaban CMS Gas Transmission Company (CMS) y LG\&E Energy Corporation, a iniciar arbitrajes bajo las reglas Centro Internacional de Arreglo de Diferencias Relativas a Inversiones (CIADI). Tanto en el caso CMS como en el LG\&E el gobierno argentino se amparó en estado de necesidad como un eximente de responsabilidad de Estado previsto en el derecho argentino, el derecho internacional y en el propio TBI entre Argentina y Estados Unidos. En ambos casos, el derecho argumentado era el mismo. Los dos tribunales alcanzaron, sin embargo conclusiones diferentes. Mientras en el laudo de CMS se rechazó el argumento, en el laudo de LG\&E se lo admitió parcialmente.

6. A. ReINISCH, "The Proliferation of International Dispute Settlement Mechanisms: The Threat of Fragmentation v. the Promise of a More Effective System? Some Reflections From the Perspective of Investment Arbitration", en International Law between Universalism and Fragmentation-Festschrift in Honour of Gerhard Hafner, Leiden-Boston, Martinus Nijhoff Publishers, 2008, pp. 107-125. 
casos en que el derecho aplicable no sea similar, pero en el que los principios de derecho aplicados reciban una diferente interpretación en la conclusión frente a hechos similares.

El no poder contar con decisiones similares a situaciones similares ya sea de hecho o de derecho afecta la previsibilidad de estas y su autoridad y consecuentemente pone en riesgo la coherencia y la confianza de este mecanismo.

Sabemos que no existe la aplicación obligatoria de la jurisprudencia en el arbitraje de inversiones, y tal como en el caso Daimler c. Argentin ${ }^{7}$ a el Tribunal estableció que probablemente nunca existiría tal obligación "dada la gran cantidad y diversos tratados aplicables a las diferentes demandas Inversor-Estado". Sin embargo, el propio Tribunal también indicó que "es un principio fundamental que casos similares sean decididos de manera similar" a menos que exista una razón suficientemente fuerte que diferencie este caso de los anteriores".

Irónicamente, en este mismo asunto, podemos encontrar decisiones inconsistentes. Existen tribunales que han rechazado firmemente la aplicación de la jurisprudencia. En el caso AES c. Argentina ${ }^{8}$ Decisión de Jurisdicción, el Tribunal sostuvo que no existe tal regla de aplicación del precedente en el derecho internacional; así como tampoco en el sistema CIADI. El Tribunal en Enron c. Argentina ${ }^{9}$ sostuvo que las decisiones CIADI y las de otros tribunales arbitrales no son una fuente primaria de derecho, por tanto, no son obligatorias para otros casos. En el caso Wintershall c. Argentina ${ }^{10}$ al citar el artículo $53^{11}$ del Convenio CIADI,

7. CIADI, Daimler Financial Services AG c. Argentine Republic, Laudo, Caso No. ARB/05/1, 22/10/2012, párr. 52.

8. CIADI, AES Corporation c. Argentine Republic, Decisión de Jurisdicción, Caso No. ARB/02/17, 26/04/2005, párr. 23.

9. CIADI, Enron Creditors Recovery Corporation (anterior Enron Corporation) y Ponderosa Assets, L.P. c. República de Argentina, Decisión de Jurisdicción, Caso No. ARB/01/3, 14/01/2004, párr. 40.

10. CIADI, Wintershall Aktiengesellschaft c. República de Argentina, Laudo, Caso No. ARB/04/14, 8/12/2008, párrs. 187 y 194.

11. CIADI, Artículo 53(1) El laudo será obligatorio para las partes y no podrá ser objeto de apelación ni de cualquier otro recurso, excepto en los casos previstos en este Convenio. Las partes lo acatarán y cumplirán en todos sus términos, salvo en la medida en que se suspenda su ejecución, de acuerdo con lo establecido en las correspondientes cláusulas de este Convenio. (2) A los fines previstos en 
el Tribunal indicó que el stare decisis ${ }^{12}$ no tiene aplicación en las decisiones de los Tribunales CIADI, ya que cada Tribunal se ha constituido ad hoc para decidir la disputa entre las partes. El Tribunal BIVAC c. Paraguay, citando nuevamente el artículo 53(1) del Convenio CIADI, indicó que las decisiones solo son obligatorias entre las partes involucradas y que el Tribunal no se encuentra sujeta a ellas como jurisprudencia obligatoria.

Otros, aunque no asumen una doctrina formal de jurisprudencia obligatoria, imponen a los árbitros la obligación de esforzarse por ser consistentes. La decisión en jurisdicción en el caso Burlington Resources v. Ecuador ${ }^{13}$, avaló el concepto de que los tribunales

[...] no está[n] obligado[s] a seguir decisiones anteriores. Al mismo tiempo, considera que debe prestar la debida atención a las decisiones anteriores de los tribunales internacionales. La mayoría cree que, sujeto a motivos convincentes en contrario, tiene el deber de adoptar soluciones establecidas en una serie de casos consistentes. Cree asimismo que, sujeto a las particularidades de un tratado determinado y de las circunstancias del caso, tiene el deber de intentar contribuir al desarrollo armonioso del derecho de inversión, satisfaciendo de este modo las expectativas legítimas de la comunidad de Estados e inversores hacia la seguridad jurídica que emana del estado de derecho. El árbitro Stern no percibe el rol de los árbitros de la misma manera ya que considera que es su deber decidir cada caso de acuerdo a sus propios méritos, con independencia de cualquier tendencia jurisprudencial aparente.

El Tribunal en el caso EDF c. Argentina ${ }^{14}$ decidió que tenía la obligación de mejorar la interpretación del lenguaje comparable aplicado a patrones similares de hechos, promoviendo con ello

esta Sección, el término "laudo" incluirá cualquier decisión que aclare, revise o anule el laudo, según los Artículos 50, 51 o 52.

12. Locución latina que se traduce como jurisprudencia vinculante.

13. CIADI, Burlington Resources Inc. c. República de Ecuador, Decisión de Jurisdicción, Caso No. $\mathrm{ARB} / 08 / 5,2 / 06 / 2010$, párr. 100.

14. CIADI, EDF International S.A., SAUR International S.A. y León Participaciones Argentinas S.A. c. República de Argentina, Laudo. Caso No. ARB/03/23, 11/06/2012, párr. 897. 
las expectativas legítimas tanto de los Estados cuanto de los inversionistas extranjeros.

Finalmente, han existido Tribunales que han puesto énfasis en la necesidad de seguir la jurisprudencia constante, cuando tal fenómeno ha surgido. El Tribunal de Quasar de Valors c. Rusia ${ }^{15}$ indicaron que los árbitros se mostrarían renuentes a separarse de una proposición seguida por una serie de decisiones ampliamente razonadas, reflejando una jurisprudencia constante. En el caso Impregilo c. Argentina ${ }^{16}$, la mayoría del Tribunal consideró que "sería desafortunado si los argumentos de valoración de [...nación más favorecida] dependieran en cada caso de las opiniones personales de cada árbitro" y "la mejor forma de evitar tal resultado es hacer la determinación en base a los precedentes jurisprudencial es cuando encontremos un claro precedente que sea aplicable". En Daimler c. Argentina ${ }^{17}$, el Tribunal consideró que uno de los factores relevantes para determinar si se siguen decisiones anteriores es el grado en el cual una clara jurisprudencia ha surgido constantemente en relación a un específico punto de derecho.

Un problema particular puede surgir cuando nos enfrentamos a procesos paralelos que se refieren a hechos y derechos similares, donde la probabilidad de llegar a decisiones inconsistentes es por lo menos alta.

Un caso concreto es el que enfrenta el Ecuador en los procesos Burlington Resources c. Ecuador y Perenco c. Ecuador, en donde ambos arbitrajes tratan sobre los mismos hechos; ambos casos versan sobre los mismos bloques petroleros: 7 y 21; y ambos casos conciernen los mismos contratos de participación.

15. SCC, Quasar de Valors SICAV S.A. et al. (Formerly Renta 4 S.V.S.A et al.) c. Russian Federation, Award on Preliminary Objections, Case No. 24/2007, 20/03/2009, párr. 16.

16. CSID, Impregilo S.p.A. c. Argentine Republic, Award, Case No. ARB/07/17, 21/06/2011, párr. 108.

17. ICSID, Daimler Financial Services AG c. Argentine Republic, Award, Case No. ARB/05/1, 22/08/2012, párr. 52. 
A pesar de dichas similitudes, es innegable que, entre otras diferencias, sobresalen dos contradicciones mayores entre las dos decisiones:

Por una parte, los tribunales han interpretado las Cláusulas de Renegociación de los Contratos de Participación para los Bloques 7 y 21 de manera diferente. Mientras que el tribunal Burlington llegó a la conclusión de que dichas cláusulas imponen la obligación de adoptar automáticamente un factor de corrección cada vez que el Estado promulgue algún nuevo tributo, el Tribunal Perenco concluyó que dicho factor de corrección solamente debe ser adoptado si el nuevo tributo afecta la economía del contrato de participación.

Por otra parte, las conclusiones de ambos tribunales son diametralmente opuestas en lo tocante al abandono de los Bloques 7 y 21 por parte del Consorcio Perenco / Burlington y la consecuente intervención del Estado. Mientras que, para el tribunal Burlington, la intervención del Ecuador en dichos Bloques ante su abandono por la Contratista debe ser calificada de "expropiación ilegal", el Tribunal Perenco llegó a la conclusión que la intervención de Ecuador en los Bloques fue totalmente legítima.

Sin duda, los casos Perenco y Burlington, se convertirán en un cas d'école de los riesgos inherentes a arbitrajes que, sobre los mismos asuntos, se desarrollan paralelamente.

Más allá de estas interpretaciones erróneas en estos dos casos paralelos, también encontramos decisiones inconsistentes en relación a la cualificación de la ley 42 en tres casos importantes para la República del Ecuador: Occidental, Burlington y Perenco.

En vista, del imprevisto incremento de los precios del petróleo a partir del 2002 se generó un desequilibrio en los contratos petroleros a nivel mundial, en vista de ello el Ecuador buscó renegociar los contratos vigentes a efectos de lograr términos más equitativos en los mismos. En respuesta a la negativa de las com- 
pañías petroleras a la renegociación, el 1 de marzo de 2006, el gobierno propuso una ley reformatoria para re-establecer el equilibrio económico de los contratos de participación. La ley contemplaba una participación de al menos el 50\% de las utilidades extraordinarias para el Estado, desde el punto en que el precio del petróleo excediera el precio contemplado en el contrato respectivo. Finalmente, el gobierno de Ecuador subió el porcentaje del $50 \%$ al $99 \%$. Como resultado de ello, muchos de los contratos de participación fueron renegociados. Aquellos inversionistas renuentes a renegociar el contrato, iniciaron arbitrajes en contra del Ecuador alegando violaciones a los contratos y a los correspondientes Tratados de Protección de Inversiones.

Tres diferentes Tribunales han conocido los asuntos relativos a la ley 42 , y un caso está todavía por resolverse. Los primeros son los Tribunales que manejan los casos de 1) Occidental Petroleum Corporation y Occidental Exploration and Production Company c. la República de Ecuador, 2) Burlington Resources Inc. c. la República de Ecuador, y, 3) Perenco Ecuador Ltd. c. la República de Ecuador y Empresa Estatal Petróleos del Ecuador (Petroecuador). Estos Tribunales llegaron a conclusiones diferentes en al menos dos puntos como son la caracterización y la naturaleza de la ley 42 y sus efectos y consecuente legalidad.

En referencia a la naturaleza de la Ley 42 el Tribunal Occidental ${ }^{18}$ sostuvo que:

A los fines de caracterizar la Ley 42, es suficiente para el Tribunal concluir, como lo hace ahora, que la participación de Ecuador en virtud de la Ley 42 "en los excedentes de los precios de venta de petróleo no pactados o no previstos" no constituye una regalía, ni un impuesto, ni un gravamen ni ninguna otra medida tributaria en los términos del Contrato de Participación. Es, como su título lo indica, una decisión unilateral del Congreso Ecuatoriano para asignar al Estado Ecuatoriano un porcentaje definido de los ingresos obtenidos por compa-

18. CIADI, Occidental Petroleum Corporation and Occidental Exploration and Production Company $v$. República de Ecuador, Laudo, Caso No. ARB/06/11, párrs. 509-510. 
ñías contratistas que, como OEPC, son titulares de un contrato de participación.

Por su parte el Tribunal Burlington ${ }^{19}$ decidió que:

Un comentario final al respecto aborda la naturaleza del impuesto en cuestión. El impuesto de la Ley 42 es un impuesto sobre las llamadas ganancias extraordinarias, es decir un impuesto que se aplica a las ganancias del petróleo superiores a las que estaban vigentes cuando se suscribieron los CP. Por definición, parecería que un impuesto tal no tiene un impacto sobre la inversión como un todo, sino solo sobre una parte de las ganancias. Asumiendo que sus efectos concuerdan con su nombre, es poco probable que un impuesto sobre las ganancias extraordinarias resulte en la expropiación de una inversión.

En comparación el Tribunal Perenco ${ }^{20}$ decidió que:

En resumen, con respecto a su efecto económico, el hecho de que obligaba el pago de dinero al Estado de conformidad con una fórmula determinada, y la definición contemporánea de Perenco de la Ley 42 como un tributo sobre el que aplicaban las cláusulas de modificación tributaria de los Contratos, el Tribunal considera que la Ley 42 debe ser tratada como una medida tributaria.

En este punto y relacionado al mismo hecho, esto es, la caracterización de la ley 42, el Tribunal de Occidental concluyó que la Ley 42 era una modificación unilateral de los términos del contrato, el Tribunal Perenco sostuvo que la Ley 42 era una medida tributaria sobre la que se aplicaban las cláusulas de modificación tributaria del contrato, y finalmente, el Tribunal Burlington decidió que la Ley 42 era un impuesto a las ganancias extraordinaria y como tal no afectaba el equilibrio económico del contrato.

19. CIADI, Burlington Resources Inc. v. República de Ecuador. Decision de responsabilidad, Caso No. $\mathrm{ARB} / 08 / 5$ [(anterior Burlington Resources Inc. y otros v. República de Ecuador y Empresa Estatal Petróleos del Ecuador (PetroEcuador)], párr. 404.

20. CIADI, Perenco Ecuador Ltd. v. La República del Ecuador y Empresa Estatal Petróleos del Ecuador (Petroecuador), Decisión en asuntos remanentes de Jurisdicción y Responsabilidad, Caso No. $\mathrm{ARB} / 08 / 6$, párr. 377. 
Ahora, en referencia al efecto de la ley 42 y su legalidad, los tres Tribunales también llegaron a diferentes conclusiones. De acuerdo al Tribunal Occidental, la Ley 42 -tanto al 50\% cuanto al 99\%- incumple la legítima expectativa del demandante y por tanto quebranta el estándar de trato justo y equitativo previsto en el Tratado de Protección de Inversiones entre Ecuador y Estados Unidos de América. En contraste, el Tribunal Perenco decidió que la promulgación de la Ley 42 no quebrantó la obligación de trato justo y equitativo contenida en el TBI entre Ecuador y Francia, sin embargo, el haber incrementado el porcentaje del $50 \%$ al 99\% si lo hizo. Por otro lado, el Tribunal Burlington sostuvo que la ley 42 -ya sea al 50\% o al 99\%- no afectó el valor de la inversión, por tanto Ecuador no expropió la inversión de Burlington pero si quebrantó el estándar de trato justo y equitativo contemplado en el TBI Ecuador-Estados Unidos.

\subsection{Legitimidad}

Sin embargo, la inconsistencia de las decisiones no es el único problema que enfrenta el arbitraje de inversiones. Otro de los problemas detectados surge del lenguaje vago y amplio constante en su norma prima (los tratados de protección de inversiones) que ha permitido a los inversionistas desafiar la normativa interna en áreas como el medio ambiente, energía y las políticas de salud. Esto sumado a la inconsistencia de las decisiones ha generado incertidumbre y desconfianza en los Estados acerca de cómo los Tribunales interpretarán estos términos en la realidad.

Ciertamente, muchos de los reclamos iniciados por los inversionistas en contra de Estados soberanos se dirigen a actos concretos. Sin embargo, cada vez más se dan casos en que los inversionistas desafían la legislación general del país anfitrión. Este fenómeno ha originado una tensión permanente entre los derechos de los inversionistas y las políticas públicas que pueden ser resueltos en detrimento del interés público. 
Aunque el interés público puede ser tomado en cuenta en la decisión arbitral, se debe considerar que los acuerdos de protección de inversiones se enfocan casi exclusivamente en los intereses del inversionista y otorgan a los inversionistas extranjeros más derechos en relación a la resolución de sus conflictos que a los inversionistas nacionales, exponen a los Estados a un riesgo de "paralización regulatoria" en la actividad política del Estado.

El que el arbitraje de inversiones se use cada vez más como una herramienta para proteger los intereses del inversionista en contra de "riesgos políticos" y políticas públicas de los Estados se ve en casos como aquel iniciado en contra de Alemania ante un Tribunal CIADI por parte del proveedor de energía de Suecia, Vattenfall ${ }^{21}$ a causa de las restricciones onerosas para una planta de energía, que infringían las promesas hechas inicialmente y las expectativas legítimas del inversionista.

Otro caso importante en este sentido es el iniciado en contra de Uruguay por la compañía Philipp Morris ante un Tribunal $\mathrm{CIADI}^{22}$, al haber Uruguay promulgado una ley que requería que las advertencias contra el consumo de cigarrillos cubriera el $80 \%$ de los empaques de los cigarrillos. También prohibía a las compañías etiquetar sus productos como "light" o "suaves".

Esto origina preguntas sobre la legitimidad de este mecanismo, preguntas que han sido realizadas cada vez más en el consenso mundial sobre si un Tribunal, designado mediante un proceso ad hoc puede tener la legitimidad suficiente como para desafiar la validez de los actos Estatales y sus consideraciones al resolver temas de alta sensibilidad política y social.

Más allá de ello, existen otros cuestionamientos al mecanismo como: en primer lugar, la independencia e imparcialidad de los árbitros y en segundo lugar, los costos y tiempo empleados en cada arbitraje.

21. CIADI, Vattenfall AB y otros c. República Federal de Alemania, Caso No. ARB/12/12.

22. CIADI, Philip Morris Brand Sàrl (Suiza), Philip Morris Products S.A. (Suiza) y Abal Hermanos S.A. (Uruguay) c. República Oriental de Uruguay, Caso No. ARB/10/7. 
En referencia al primero, estas discusiones se originan en el hecho de su forma de designación evaluando simpatías y antipatías hacia los casos. Su interés de ser designados nuevamente en casos futuros y el hecho de que muchos de ellos juegan un doble papel en el mecanismo, siendo algunas veces árbitros y otras abogados de parte. Al respecto, se ha observado la creación de una comunidad cerrada formada por árbitros expertos, en un reciente estudio realizado por Sergio PUIG, se revela una densa red que refuerza los estándares predominantes y comportamientos que aíslan a sus más importantes miembros de la influencia externa ${ }^{23}$.

En relación al segundo, los costos de los procedimientos de arbitraje son elevados. Así, los Estados deben soportar una carga presupuestaria elevada para ejercer su defensa, eso sumado al hecho de que un proceso arbitral de inversiones puede durar mucho más que un proceso doméstico si tomamos en cuenta que no existe fase de apelación, deslegitimiza más el mecanismo. A modo de ejemplo y utilizando para ello, un método de cálculo disponible en la red ${ }^{24}$, un arbitraje CIADI cuyo monto en discusión asciende a la suma de US\$500'000.000,00, con un Tribunal compuesto por tres árbitros, con un nivel de complejidad medio y con abogados corporativos americanos puede llegar a costar a cada parte US\$ 3'964.456,90 y puede tener una duración de 4 años.

\section{REFORMAS AL ARBITRAJE DE INVERSIONES}

Ante esta serie de problemas se han planteado varias soluciones como: i) acudir a las interpretaciones oficiales de los tratados; ii) Laudos preliminares; iii) Apelación en cada TBI; iv) Instancia de apelación.

En referencia a acudir a las interpretaciones oficiales de los tratados a efectos de unificar los conceptos utilizados en los mis$\operatorname{mos}^{25}$, esta opción permite que sean los propios Estados suscrip-

23. S. PuIg, "Social Capital in the Arbitration Market", The European Journal of International Law, Vol. 25 (2), p. 390.

24. Véase $<$ https://goo.gl/G2Yg31 $>$. 
tores quienes definan su intención al suscribir los mismos, sin embargo, esta solución enfrenta dos problemas, el primero de ellos radica en que los dos Estados deben requerir su interpretación, para así acudir al mecanismo contemplado en la Convención de Viena para la interpretación de los Tratados ${ }^{26}$, situación muy difícil en casos en los que se encuentra un arbitraje en marcha cuyo resultado se vería afectado por este mecanismo ${ }^{27}$ y el segundo es que la única forma de obviar esto, es que en el propio tratado se contemple la posibilidad de un mecanismo de interpretación regulado que opere de manera inmediata, esto es, una cláusula similar a la constante en el NAFTA que cree una instancia especialmente diseñada para ello, sin que requiera transitar hacia la anuencia de los países requeridos.

La segunda alternativa sería simular la experiencia de la Comunidad Europea para la aplicación de su ley comunitaria, y que consiste en someter a un tribunal permanente decisiones sobre cuestiones preliminares durante el proceso y de esta manera ir encauzando el laudo final, nuevamente para la implementación de este mecanismo se requeriría de la reforma necesaria a los tratados a efectos de que sea contemplada, con el requerimiento adicional de que para ello debería definirse de manera exhaustiva cómo funcionaría dicho tribunal permanente.

La tercera opción consiste en establecer en cada TBI un sistema de apelación a efectos que una vez dictado el laudo correspondiente, de existir apelación se constituya un Tribunal para el efecto. Esta opción conlleva varios problemas y riesgos, el primero de ellos es la necesaria reforma de los tratados para su inclusión y la segunda es que no se solucione la inconsistencia que genera tal medida ya que cada órgano de apelación podría emitir decisiones diferentes.

25. Un ejemplo de ello es los provisión constante en el artículo 1131 (2) del Tratado de Libre Comercio de América del Norte (NAFTA 1994) que prevé que las interpretaciones efectuadas por Comisión de Libre Comercio, compuesta por tres ministros de comercio de distintos Estados miembros, son obligatorias.

26. Convención de Viena sobre el Derecho de los Tratados (1969).

27. Caso Ecuador c. EEUU, en donde el pedido de Ecuador falló en vista del silencio del gobierno de los Estados Unidos de América. 
Finalmente, se plantea la posibilidad de crear algún procedimiento de apelación a través de la creación de una Corte Permanente de Arbitraje de Inversiones. Esta iniciativa sería viable en acuerdos multilaterales como es el caso del CIADI, al respecto la Secretaría del CIADI describió un posible mecanismo de apelación en un documento emitido en octubre de $2014^{28}$ en donde propone establecer Tribunales de árbitros permanentes que se encargarían de conocer las apelaciones interpuestas por las partes afectadas, dicho mecanismo enfrenta nuevamente varios problemas para su implementación. En primer lugar el incremento en duración de los arbitrajes y los costos inherentes a ello; en segundo, la necesidad de que para su implementación se cuente con una renegociación de los términos de los acuerdos de arbitraje vigentes.

\subsection{La reforma a los tratados}

Todo ello ha planteado una necesidad cada vez más creciente de darle legitimidad al mecanismo a través de la reforma de este desde su origen, esto es, ir directamente hacia la incorporación en los tratados de protección de inversiones de puntos específicos como desarrollo sostenible y definiciones claras y precisas sobre los términos de protección a los inversionistas como: inversión, trato justo y equitativo, expropiación indirecta, nación más favorecida y excepciones para ellas como políticas públicas, seguridad nacional, crisis de balanza de pagos, derechos humanos, derechos de comunidades indígenas, medio ambiente. Se ha planteado también como una alternativa la creación de una Corte permanente de apelaciones en inversiones que coexista con el mecanismo de resolución de conflictos inversionistas-Estado establecido en los diferentes TBI y Acuerdos de Comercio ${ }^{29}$.

28. International Centre for Settlement of Investment Disputes (ICSID), Possible Improvements of the Framework for ICSID Arbitration, Disccussion Paper, 22/10/2004. Véase < https://goo.g1/aXrxiS >.

29. Temas tratados en la conferencia de la UNCTAD sobre "La Transformación del Régimen Internacional de Acuerdos sobre Inversiones", celebrada del 25 al 27 de febrero de 2015 en Ginebra. 
En seguimiento a ello, la UNCTAD ha planteado la opción de reformar el mecanismo existente de arbitraje ad hoc para disputas inversionista-Estado y ha contemplado las siguientes opciones:

- Mejorar el proceso arbitral.- Haciéndolo cada vez más transparente y coordinado, desalentando la presentación de reclamos infundados y tomando en cuenta las preocupaciones acerca del nombramiento de los árbitros y sus potenciales conflictos.

- Limitar el acceso a los inversionistas.- Reduciendo las materias objeto de reclamo, fijando límites de tiempo, previniendo el abuso de las compañías de papel.

- Usar filtros para canalizar casos sensibles a solución de controversias Estado-Estado.

- Introducir la obligación de litigar localmente como una condición previa para acudir al arbitraje internacional.

- Introducir el sistema de apelación, ya sea bilateral, regional o multilateral.

- Crear una Corte Internacional de Inversiones.

- Reemplazar el arbitraje internacional de inversiones por soluciones de controversias Estado-Estado.

- Reemplazar el arbitraje internacional de inversiones por soluciones de controversias domésticas.

Esta propuesta para ser canalizada involucra nuevas negociaciones de tratados vigentes, negociaciones que en muchos casos involucran fuertes acercamientos políticos para que sean concluidas, a más de ello, envuelven un renunciamiento por parte de los inversionistas, con una gran capacidad de cabildeo político, a derechos que ya han conquistado en los tratados ya suscritos. 


\subsection{La inclusión de una fase de apelación dentro del Tratado Transatlántico de Comercio e Inversiones entre la Unión Europea y Estados Unidos}

Varias razones jurídicas, económicas y políticas generan el surgimiento de una tesis, cada vez más sólida, para incluir el recurso de apelación que permita recurrir de la resolución de la decisión arbitral, en el caso del TTIP se busca incluir un mecanismo bilateral similar al de la Organización Mundial del Comercio (OMC).

La Comisión ha recibido una sugerencia del parlamento europeo en el sentido de:

sustituir el mecanismo de resolución de litigios entre inversores y Estados por un nuevo sistema para resolver las diferencias entre los inversores y los Estados que esté sujeto a los principios y el control democráticos, en que los posibles asuntos sean tratados de forma transparente por jueces profesionales, independientes y designados públicamente en audiencias públicas, y que incluya un mecanismo de apelación en el que se garantice la coherencia de las decisiones judiciales, se respete la jurisdicción de los tribunales de la UE y de los Estados miembros, y los intereses privados no puedan menoscabar los objetivos en materia de políticas públicas ${ }^{30}$.

$\mathrm{Al}$ respecto, el texto propuesto por la Comisión pretende cubrir entre otros los siguientes puntos ${ }^{31}$ :

1. Normas claras aplicadas por jueces imparciales a través de un proceso transparente y neutral de interés de los Estados y los inversores

- La propuesta de la UE aclara el contenido de las normas sustantivas de protección y la forma en que se preserva cabalmente el derecho de regular en el interés público. Esto representa una mayor seguridad jurídica para los inversores y los gobiernos. Los gobiernos pueden regular en el interés público. Los inversores también pueden benefi-

30. A. GuAmán, TTIP: El asalto de las multinacionales a la democracia. Ediciones, 1ra. Ed., Akal, 2015.

31. Boletín de prensa emitido por la Comisión Europea, noviembre de 2015. 
ciarse de normas más claras, ya que estarán protegidos contra posibles abusos (por ejemplo, la expropiación sin compensación, acoso, etc.) y evitarán la pérdida de tiempo y recursos al tratar de conseguir casos que no valen la pena.

- Al igual que el arbitraje internacional, el Sistema Judicial de Inversiones (ICS, por sus siglas en inglés) prevé una sede neutral para el arreglo de diferencias relativas a inversiones.

2. Un sistema de resolución de controversias de inversión con costos más eficientes y con más celeridad

- El sistema tiene plazos procesales claros para garantizar la solución de controversias rápida y para mantener los costos bajos. En las controversias de inversión, los principales costos para las partes involucradas en un conflicto son los honorarios de abogados externos (asesores jurídicos), que representan alrededor del $80 \%$ de los costes totales de una disputa. Aquí las normas sustantivas claras ayudarán a mantener controlados los reclamos - y por lo tanto el nivel de litigios.

- Los procedimientos generales con arreglo al ICS, incluyendo la apelación, se limitan a 2 años (el Tribunal de Primera Instancia debe decidir dentro de los 18 meses y el Tribunal de Apelaciones dentro de los 6 meses).

A modo de comparación, la duración promedio de los procedimientos en virtud de los tratados de inversión existentes es de 3 a 4 años, y la anulación (por razones de procedimiento) podría añadir alrededor de otros 2 años, lo que significa que la duración total a menudo es de alrededor de 6 años (con muchos que toman más tiempo).

- Los sueldos de los miembros del Tribunal de Apelaciones lo pagaría exclusivamente la UE y los EEUU; habría un límite para las tasas diarias de los jueces, en lugar de dejar que esto sea negociado entre las partes contendientes como es el caso en el marco del sistema de ISDS actual.

- Es evidente que existen causales definidas para la apelación a efectos de asegurar que el sistema de apelación no 
sea sujeto de abusos por la parte perdedora. Estos son: (a) que el Tribunal ha incurrido en un error en la interpretación o aplicación de la ley aplicable en el acuerdo TTIP; (b) que el Tribunal ha incurrido en un error manifiesto en la apreciación de los hechos; y (c) razones procesales (es decir, causales comparables a los procedimientos de anulación).

Frente a esta propuesta sectores de los Estados Unidos de América, como la Cámara de Comercio de Estados Unidos ${ }^{32}$, han reaccionado defendiendo el actual mecanismo de solución de controversias implementado a través del Centro Internacional de Arreglo de Diferencias relativas a Inversiones (CIADI), como una herramienta para el fortalecimiento del derecho internacional y cuestionando la propuesta como una forma de debilitar la protección al inversionista y la vigencia del derecho internacional. Adicionalmente, argumentan que el mecanismo está aplicando sus propios correctivos por lo que no es necesario la implementación de una Corte como una especie de experimento que traería más problemas que soluciones.

Otros sectores de la Unión Europea ${ }^{33}$ han criticado fuertemente el modelo presentado argumentando lo siguiente:

1. Los tribunales arbitrales nacieron para resolver conflictos entre Estados; al permitir que únicamente las empresas sean las que demanden a los Estados y no existir una previsión formal por la que el Estado receptor puede demandar al inversor extranjero. Se crea una asimetría que vicia la solución.

2. No existe una opción para que las personas naturales y pueblos que sufren vulneraciones de sus derechos por las prácticas de las empresas puedan interponer sus denuncias.

3. El Investment Court System presentado por la Comisión no nombra ni una sola vez los derechos humanos, laborales, medioambientales, sociales, culturales[...]Los jueces del mencionado tribunal deberán aplicar, fundamentalmente, las normas de comercio e inversiones que el TTIP contenga.

32. Véase más en $<$ https://goo.gl/AgaT10 $>$.

33. Véase más en $<$ http://goo.gl/wNxVE4>. 
4. El planteamiento de la Comisión se construye sobre el concepto de seguridad jurídica vinculado a la lex mercatoria, ya que su único fundamento resulta ser la protección de los contratos y la defensa de los intereses comerciales de las compañías multinacionales. Se pretende proteger las inversiones de las multinacionales extranjeras, eludiendo la normativa internacional, comunitaria y nacional de los derechos humanos, sociales y medioambientales y la competencia de los tribunales nacionales e internacionales.

5. Las normas que tutelan los derechos de los inversionistas son muy precisas, detalladas y numerosas. Se regulan las obligaciones contractuales adquiridas por los Estados elevando a categoría fundamental, el principio jurídico de pacta sunt servanda ("lo pactado obliga"), en tanto que sirve de base para blindar los contratos firmados por las empresas transnacionales. Al mismo tiempo, se obvian y rechazan las cláusulas rebus sic stantibus ("lo establecido en los contratos lo es en función de las circunstancias concurrentes en el momento de su celebración") y otros usos y principios internacionales universales como los de equidad, buena fe y enriquecimiento injusto; toda norma o principio jurídico que defienda los intereses de las mayorías sociales quedan fuera de la proposición de la Comisión.

6. La definición del término inversión es muy amplia y se identifica con los activos, de forma que encierra acciones y otras formas de participación en sociedades, derechos derivados de todo tipo de aportes con el fin de crear valor económico, bienes muebles e inmuebles, derechos reales, propiedad intelectual e industrial, servicios públicos, concesiones otorgadas por ley o contrato, incluidas las que alcanzan a la prospección, extracción o explotación de recursos naturales, y se asocia al concepto de ganancia de una empresa mediante la expropiación indirecta. Por tanto, no sólo comprende las inversiones reales, sino que abarca especulaciones en deuda soberana, inversiones especulativas, inversiones en bienes intangibles... Además, se protege toda expectativa "legítima" de ganancia.

La expropiación indirecta implica que toda medida, ley, reglamento, acto administrativo que provoque daño en el patrimonio del inversor deberá ser compensado. 
7. El principio de Trato Justo y Equitativo se mantiene como eje central de la propuesta de la Comisión. Por otra parte, se permite a las empresas demandar a los Estados no solo por incumplimientos del tratado si no por incumplimientos contractuales de un acto soberano no comercial, como las políticas públicas.

8. La Comisaría Europea ha manifestado que la reforma propuesta no afectará al sistema arbitral previsto en el Acuerdo Económico y Comercial Global entre la UE y Canadá (CETA). Tal afirmación implica que las empresas transnacionales de EE.UU. y las de terceros países -a través de sus filiales con sede en Canadá o en países de la UE- podrán activar el sistema arbitral tradicional establecido en el CETA.

9. En la propuesta de la Comisión Europea, las modificaciones que países como India, Indonesia y Sudáfrica están proponiendo -después de evaluar los impactos de los tratados de inversiones y comercio firmados en los últimos años- han sido totalmente ignoradas.

\section{Conclusiones}

En vista de todo lo expresado se concluye sin lugar a dudas que el problema de la consistencia de las decisiones arbitrales es un tema que no permite aplazamiento y que su falta de solución tomando en cuenta el cada vez más creciente número de arbitrajes de inversiones y las decisiones que en este se dan sin que haya una columna vertebral que las guíe claramente hacia una coherencia del mecanismo en general, deslegitima profundamente el sistema.

Cualquier solución necesariamente deberá pasar por una reforma integral del mecanismo, reforma que resulta difícil en función de la amplia gama y clases de tratados de protección de inversiones, sin tomar en cuenta que los nuevos acuerdos comerciales incluyen a su vez mecanismos de arreglo de disputas que no necesariamente llenan tales vacíos y necesidades. 
Este es un mecanismo largo y tortuoso, que ha tenido y tiene iniciativas varias, que sólo con el tiempo se verá si efectivamente solucionan los grandes cuestionamientos considerados. 